BMJ Open

Sport \&

Exercise

Medicine

\section{Validity of estimating physical activity intensity using a triaxial accelerometer in healthy adults and older adults}

To cite: Nagayoshi S, Oshima Y, Ando $\mathrm{T}$, et al. Validity of estimating physical activity intensity using a triaxial accelerometer in healthy adults and older adults. BMJ Open Sport \& Exercise Medicine 2019;5:e000592. doi:10.1136/ bmjsem-2019-000592

Accepted 14 September 2019

Check for updates

(C) Author(s) (or their employer(s)) 2019. Re-use permitted under CC BY. Published by BMJ.

${ }^{1}$ Omron Healthcare Co Ltd, Muko, Japan

${ }^{2}$ Graduate School of HumanEnvironment Studies, Kyushu University, Fukuoka, Japan ${ }^{3}$ Faculty of Humanities and Social Sciences, University of Marketing and Distribution Sciences, Kobe, Japan ${ }^{4}$ Department of Nutrition and Metabolism, National Institute of Health and Nutrition, National Institutes of Biomedical Innovation, Health and Nutrition, Shinjuku, Japan

${ }^{5}$ Department of Nutritional Epidemiology and Shokuiku, National Institute of Health and Nutrition, National Institutes of Biomedical Innovation, Health and Nutrition, Shinjuku, Japan

${ }^{6}$ Graduate School of Engineering Science, Osaka University, Toyonaka, Japan

${ }^{7}$ Faculty of Sport Sciences, Waseda University, Tokorozawa, Japan

${ }^{8}$ Center for Health Science and Counseling, Kyushu University, Fukuoka, Japan

Correspondence to

Sho Nagayoshi;

sho.nagayoshi@omron.com

\section{ABSTRACT}

Background A triaxial accelerometer with an algorithm that could discriminate locomotive and non-locomotive activities in adults has been developed. However, in the elderly, this accelerometer has not yet been validated. The aim were to examine the validity of this accelerometer in the healthy elderly, and to compare the results with those derived in a healthy younger sample.

Methods Twenty-nine healthy elderly subjects aged 60-80 years (Elderly), and 42 adults aged $20-59$ years (Younger) participated. All subjects performed 11 activities, including locomotive and non-locomotive activities with a Douglas bag while wearing the accelerometer (Active style Pro HJA-750C). Physical activity intensities were expressed as metabolic equivalents (METs). The relationship between the METs measured using the Douglas bag and METs predicted using the accelerometer was evaluated.

Results A significant correlation between actual and predicted METs was observed in both Elderly $(r=0.85$, $\mathrm{p}<0.001)$ and Younger $(\mathrm{r}=0.88, \mathrm{p}<0.001)$. Predicted METs significantly underestimated compared with actual METs in both groups $(p<0.001)$. The mean of the errors was $-0.6 \pm 0.6 \mathrm{MET}$ in Elderly and $-0.1 \pm 0.5 \mathrm{MET}$ in Younger. The degree of underestimation increased with increasing METs in Elderly $(p<0.001)$. A stepwise multiple regression analysis revealed that predicted METs, age, and weight were related to actual METs in both groups.

Conclusion The degree of correlation between predicted and actual METs was comparable in elderly and younger participants, but the prediction errors were greater in elderly participants, particular at higher-intensity activities, which suggests that different predicting equations may be needed for the elderly.

\section{BACKGROUND}

The elderly population has increased worldwide. . In particular, in Japan in 2017, over 35.2 million people were aged 65 years or over, constituting $27.7 \%$ of the total population and marking a record high. ${ }^{2}$ WHO Global Burden of Disease estimates show that the prevalence of disability, which included impairments, activity limitations, and participation restrictions, increases with age and suggests that more than $46 \%$ of people aged 60 years and over have disabilities. ${ }^{3}$ It is well
What are the new findings

- The validity of a triaxial accelerometer developed based on data from aged 20 to 59 years was examined in the healthy elderly.

- A strong correlation was found between actual metabolic equivalents (METs) measured using Douglas bag and predicted METs using a triaxial accelerometer in the healthy elderly.

- In the healthy elderly, predicted METs were underestimated and the degree of underestimation increased with increasing METs.

known that moderate to vigorous intensity physical activity (MVPA) plays an important role in preventing disability in elderly people. ${ }^{4}$ The WHO recommendation for physical activity for the elderly demonstrated that people aged 65 years and over should do at least $150 \mathrm{~min}$ of moderate-intensity aerobic physical activity throughout the week, or do at least $75 \mathrm{~min}$ of vigorous-intensity aerobic physical activity throughout the week, or an equivalent combination of moderate-intensity and vigorous-intensity activity. ${ }^{4}$ Besides, as the most recent study indicated, the elderly have fewer opportunities to reach MVPA, ${ }^{5}$ assessment of light activities, such as household activity other than walking, would also be important. Furthermore, it has been reported that sedentary behaviour of 1.5 metabolic equivalents (METs) or less is related to all-cause mortality in older adults. ${ }^{6}$ From these reports, it seems that measuring the intensity of physical activities is important for physical activity management for elderly people.

Although multiple subjective and objective methods have been proposed for measuring physical activity, questionnaires are a practical, easy to administer to large groups, and cost-efficient method. However, they are prone to either overestimation or underestimation due to inaccurate recall, social desirability, and misinterpretation. ${ }^{7}$ In the 
elderly, self-reports and questionnaire surveys were found to be affected by the state of health and cognitive function; ${ }^{8}$ therefore, objective methods are considered more desirable for measuring physical activity.

Recently, accelerometers that can measure both total amount of physical activity and intensity level per unit time have been widely used for research as a means of objective assessment of physical activity in free-living conditions. An accelerometer is a device for assessing physical activity using equations developed from the relationship between the acceleration data and the energy consumption obtained by expired gas analysis. Acceleration sensors have been previously mounted mainly with a single vertical axial sensor, but they can be mounted with a triaxial sensor. Moreover, some of the latest studies have been designed to identify the types of physical activity by assessing information derived from the acceleration data. $^{9-12}$

Several types of accelerometers are now marketed, and many devices have been validated in the literature. ${ }^{13-19}$ However, few studies have examined the validity of accelerometer data in elderly subjects, and most have only examined the intensity during walking and MVPA cut-points. ${ }^{151619}$

A triaxial accelerometer with an algorithm that could discriminate locomotive and non-locomotive activities in adults has been developed. ${ }^{12}{ }^{20}$ However, in the elderly, this accelerometer has not yet been validated. Therefore, the aim were to examine the validity of this accelerometer in the healthy elderly, and to compare the results with those derived in a healthy younger sample.

\section{SUBJECTS AND METHODS Subjects}

Twenty-nine healthy Japanese elderly subjects aged 60-80 years (Elderly: 15 males and 14 females) participated in this study. In the initial recruitment, 30 elderly subjects participated, but one was excluded due to lack of data. To clarify the validity of the results in the elderly, 42 Japanese adults aged 20-59 years (Younger: 22 males and 20 females) also participated. A total of 71 subjects participated in this study. The number of subjects was determined based on a previous study. ${ }^{20}$ Subjects were recruited from subject recruitment companies and related organisations of researchers. Subjects were recruited with the same ratio of male to female and adjustment for body mass index (BMI) in each age bracket to the standard Japanese BMI. This study was conducted in accordance with the guidelines set by the Declaration of Helsinki.Subjects were excluded from the study if they had any contraindication for exercise or if they were physically unable to complete the activities.

\section{Anthropometric measurements}

Body weight was measured using a digital scale to the nearest $0.1 \mathrm{~kg}$, with the subjects dressed in light clothing. Barefoot standing height was measured to the nearest $0.1 \mathrm{~cm}$ using a wall-mounted stadiometer. BMI was calculated as body weight $(\mathrm{kg})$ divided by height squared $\left(\mathrm{m}^{2}\right)$.

\section{Experimental protocol}

Subjects visited the laboratory after fasting for 12 hours or more in the morning of the day of the experiment. After anthropometric measurements, they performed 11 sequences of normal daily activities with a face mask and Douglas bag while wearing a triaxial accelerometer on the right side of the waist in a controlled laboratory setting. The activities were selected based on a previous study ${ }^{20}$ and several normal daily activities for the elderly were added. The selected activities were as follows: resting in the sitting position as a resting metabolic rate (RMR), filing of documents in a sitting position, filing of documents in a standing position, wiping down, dish washing, hanging and taking in the laundry, vacuuming, radio calisthenics, slow walking (Elderly: $50 \mathrm{~m} / \mathrm{min}$, Younger: $55 \mathrm{~m} / \mathrm{min}$ ), normal walking (both groups: $70 \mathrm{~m} / \mathrm{min}$ ) and fast walking (Elderly: $90 \mathrm{~m} / \mathrm{min}$, Younger: $100 \mathrm{~m}$ / $\min$ ) on a track. These activities were chosen as representative activities of daily life. The subjects were permitted to consume only water during the experiment. They were instructed to lie down quietly for $30 \mathrm{~min}$, and then RMR in the sitting position for $7 \mathrm{~min}$ twice or more. The other activities were subsequently performed for 4-8 min. There was sufficient rest between the activities to eliminate any carry-over effects from one activity to the next. The expired air during each activity from each subject was collected under a steady state in the last $1.5-7 \mathrm{~min}$.

\section{Indirect calorimetry}

During each activity, the expired air was collected in a Douglas bag. Expired $\mathrm{O}_{2}$ and $\mathrm{CO}_{2}$ gas concentrations were measured using a mass spectrometer (ARCO-2000; Arco System, Kashiwa, Japan), and gas volume was calculated using a certified dry gas metre (DC-5; Shinagawa, Tokyo, Japan). For each measurement, the gas analyser was initially calibrated using a certified gas mixture and atmospheric air. The energy expenditure (EE) was estimated from $\mathrm{VO}_{2}$ and $\mathrm{VCO}_{2}$ using Weir's equation. ${ }^{21}$ Reference MET values were calculated as the EE during the activities divided by the measured RMR.

\section{Triaxial accelerometer}

An Active style Pro HJA-750C (ASP) (Omron Healthcare Co., Ltd. Kyoto, Japan) was used in this study. The HJA-750C is a successor to the HJA-350IT, the principles and the validity were reported in previous studies. ${ }^{12} 20$ Both models were mounted with the same acceleration sensor (LIS3LV02DQ; ST-Microelectronics, Geneva, Switzerland) and algorithm ${ }^{12}{ }^{20}$ (see figure 1 in ref. 20 for the workflow of the algorithm). The device, a Micro Electro Mechanical Systems-based triaxial accelerometer, measured $52 \times 40 \times 12 \mathrm{~mm}$, weighed approximately $23 \mathrm{~g}$, including the battery. Triaxial acceleration was measured with a sensitivity of $3 \mathrm{mG}$ at a sampling rate of $32 \mathrm{~Hz}$. Each of the three signals from the triaxial accelerometer was 
passed through a high-pass filter with a cut-off frequency of $0.7 \mathrm{~Hz}$ to remove the gravitational acceleration component from the signal. The integral of the absolute value of each three axes acceleration signals was calculated over $10 \mathrm{~s}$ intervals. This device uses three equations to calculate the intensity of activity according to the type of activity. The equations and their validity were previously described. ${ }^{12} 20$

\section{Statistical analysis}

All values are presented as means and SD. Differences were considered to be significant if the p-value was less than 0.05. Elderly and Younger were compared using an unpaired t-test. The relationship between the METs measured using the Douglas bag method (DB_METs) and METs predicted using the ASP (ASP_METs) was evaluated using Pearson's correlation coefficient ( $\mathrm{r}$ ). DB_METs and ASP_METs within a group were compared using the paired t-test. The validity of ASP was expressed as error (ASP_METs-DB_METs), error rate ((ASP_METsDB_METs)/DB_METs $\times 100)$ ) and error plots. Stepwise multiple regression analysis was also carried out to evaluate factors related to DB_METs. DB_METs was applied as dependent variables, and age, sex, weight, BMI and ASP_METs were applied as independent variables.

All statistical analyses were performed using IBM SPSS Statistics V.24.0 for Windows.

\section{RESULTS}

Physical characteristics and RMR in the sitting position are shown in table 1. Although no significant difference was observed in body weight between the groups, RMR in the sitting position of Elderly was significantly lower than that of Younger $(p<0.01)$.

DB_METs during activities in both groups are shown in table 2. All values were significantly higher in Elderly for all daily activities.

The relationships between DB_METs and ASP_METs in Elderly (figure 1A) and Younger (figure 1B) are shown separately. A significant correlation was observed in both Elderly $(\mathrm{r}=0.85, \mathrm{p}<0.001)$ and Younger $(\mathrm{r}=0.88, \mathrm{p}<0.001)$. ASP_METs significantly underestimated compared with DB_METs in both groups (Elderly: DB_METs $=3.2 \pm 1.1$ METs, ASP_METs $=2.6 \pm 0.8$ METs $(\mathrm{p}<0.001)$, Younger:
Table 2 DB_METs during the activities in Elderly and Younger

$\begin{array}{ll}\text { Elderly } & \text { Younger } \\ \text { (60-80years) } & \text { (20-59years) }\end{array}$

Filing of documents $1.6 \pm 0.2(1.3-2.0) \quad 1.5 \pm 0.2(1.2-2.7)^{\star}$ in a sitting position

Filing of documents $2.3 \pm 0.3(1.8-2.8) \quad 2.1 \pm 0.4(1.4-3.0)^{*}$ in a standing position

\begin{tabular}{lll} 
Wiping down & $3.0 \pm 0.6(2.1-4.6)$ & $2.6 \pm 0.5(1.7-4.3)^{\star \star}$ \\
\hline Dish washing & $2.3 \pm 0.3(1.8-3.2)$ & $2.1 \pm 0.4(1.4-3.1)^{\star}$ \\
\hline $\begin{array}{l}\text { Hanging and taking } \\
\text { in the laundry }\end{array}$ & $2.8 \pm 0.4(2.2-3.6)$ & $2.5 \pm 0.5(1.7-3.8)^{\star \star}$ \\
\hline Vacuuming & $3.4 \pm 0.7(1.9-5.1)$ & $3.0 \pm 0.7(1.9-5.1)^{\star}$ \\
\hline Radio callisthenics & $3.7 \pm 0.6(2.5-4.9)$ & $3.2 \pm 0.5(2.2-4.4)^{\star \star \star}$ \\
\hline Normal walking & $4.1 \pm 0.6(3.1-5.8)$ & $3.7 \pm 0.5(2.8-5.3)^{\star \star}$ \\
\hline Slow walking & $3.6 \pm 0.5(2.9-5.2)$ & $3.3 \pm 0.5(2.4-5.2)$ \\
\hline Fast walking & $5.1 \pm 0.8(3.3-6.9)$ & $5.1 \pm 0.8(3.7-6.9)$ \\
\hline
\end{tabular}

Mean $\pm S D$ (minimum-maximum). ${ }^{*} \mathrm{p}<0.05,{ }^{* *} \mathrm{p}<0.01,{ }^{* * *} \mathrm{p}<0.001$. Slow walking and fast walking were excluded from statistical analyses because the walking speed differed between the groups. Slow walking (Younger: $55 \mathrm{~m} / \mathrm{min}$, Elderly: $50 \mathrm{~m} / \mathrm{min}$ ), normal walking (both groups: $70 \mathrm{~m} / \mathrm{min}$ ) and fast walking (Younger: $100 \mathrm{~m} /$ min, Elderly: $90 \mathrm{~m} / \mathrm{min}$ ).

DB_METs, metabolic equivalents (METs) measured using the Douglas bag method.

DB_METs $=2.9 \pm 1.1 \quad$ METs, ASP_METs $=2.8 \pm 1.1 \quad$ METs $(p<0.001))$. In addition, the mean of the errors was $-0.6 \pm 0.6$ METs in Elderly and $-0.1 \pm 0.5$ METs in Younger, indicating significantly greater underestimation of the ASP_METs for Elderly $(\mathrm{p}<0.001)$.

The error plots of ASP_METs (ASP_METS - DB_METs) are shown in figure 2. The degree of underestimation by the ASP increased with increasing METs in Elderly $(\mathrm{p}<0.001)$.

The errors and error rate of the ASP_METs compared with the DB_METs in both groups are shown in table 3 . The estimated error was significantly higher in Elderly for all activities except for filing documents while sitting or standing.

Stepwise multiple regression analysis was performed to evaluate factors related to DB_METs. Age, sex, weight,

Table 1 Physical characteristics and RMR in the sitting position in Elderly and Younger

\begin{tabular}{lll} 
& $\begin{array}{l}\text { Elderly (60-80years) } \\
(\mathbf{n = 2 9 )}\end{array}$ & $\begin{array}{l}\text { Younger (20-59years) } \\
(\mathbf{n = 4 2 )}\end{array}$ \\
\hline Sex (male/female) & $15 / 14$ & $22 / 20$ \\
\hline Age (years ) & $72.3 \pm 5.5(61-80)$ & $38.4 \pm 10.9(21-55)^{\star \star \star}$ \\
\hline Height $(\mathrm{cm})$ & $158.8 \pm 10.5(139.5-179.0)$ & $165.0 \pm 8.8(148.3-182.1)^{\star \star}$ \\
Weight $(\mathrm{kg})$ & $60.0 \pm 11.2(43.2-92.9)$ & $61.9 \pm 13.8(32.1-91.8)$ \\
BMI $\left(\mathrm{kg} / \mathrm{m}^{2}\right)$ & $23.8 \pm 3.2(16.7-30.6)$ & $22.6 \pm 3.8(14.6-32.0)$ \\
\hline RMR $(\mathrm{kcal} / \mathrm{min})$ & $0.82 \pm 0.13(0.55-1.24)$ & $0.94 \pm 0.18(0.58-1.44)^{\star \star}$ \\
\hline
\end{tabular}

Mean \pm SD (minimum-maximum). ${ }^{*} \mathrm{p}<0.01,{ }^{* * *} \mathrm{p}<0.001$.

BMI, body mass index; RMR, resting metabolic rate. 
A Elderly

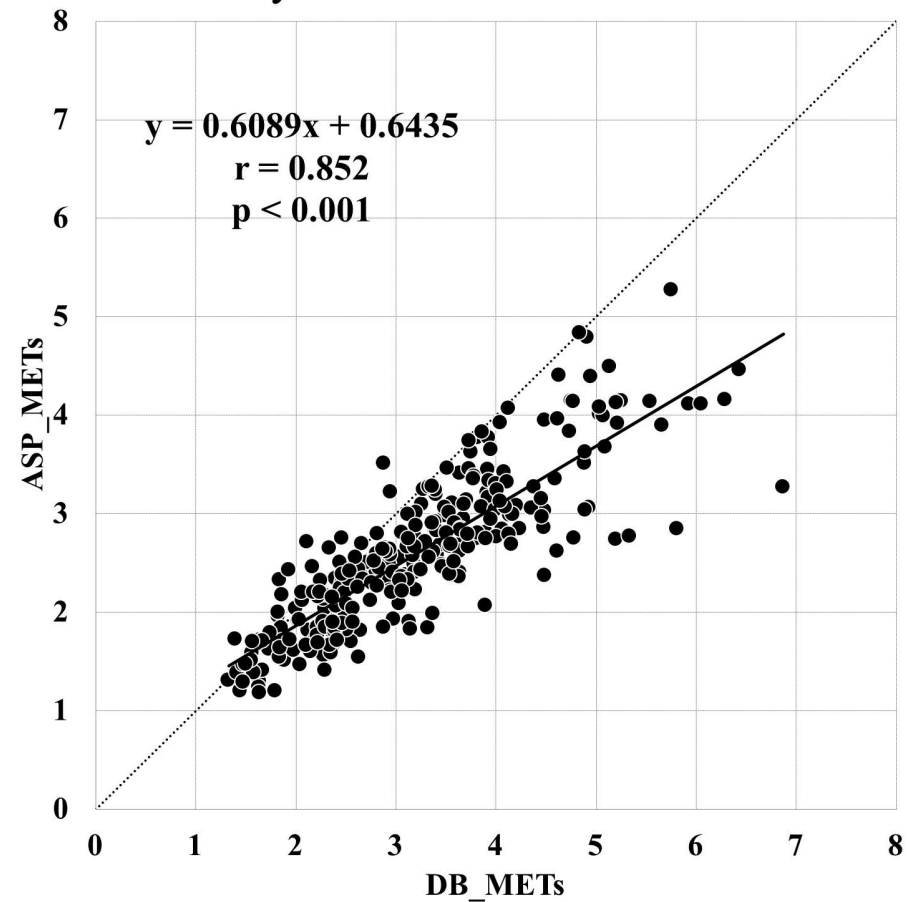

B Younger

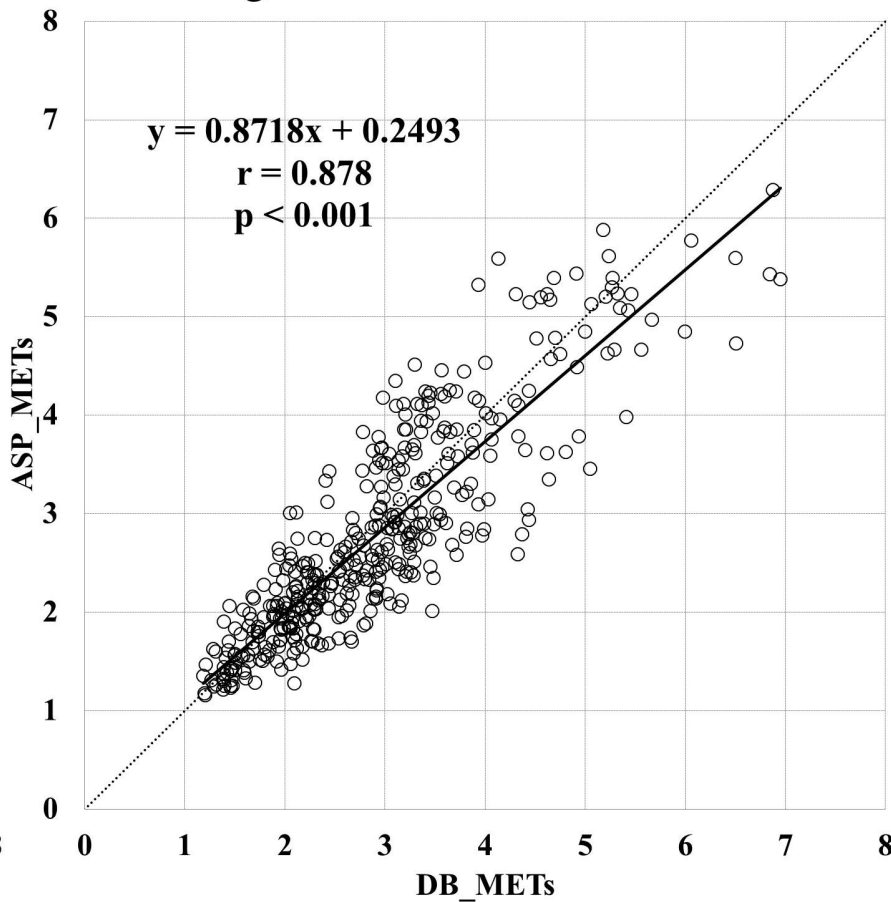

Figure 1 Relationship between the DB_METs and ASP_METs in Elderly (A) and Younger (B). ASP_METs, METs predicted using Active style Pro HJA-750C;DB_METs, metabolic equivalents (METs) measured using the Douglas bag method; Elderly, elderly group aged $60-80$ years; Younger, adult group aged $20-59$ years.

BMI and ASP_METs were applied as independent variables. As a result, DB_METs in both groups were found to be related to ASP_METs, age and weight (table 4). Since age was selected prior to body weight by stepwise analysis, the influence of age on the prediction of DB_METs was obvious in Elderly and the partial regression coefficient of age in the model 3 for Elderly was significantly greater than that for Younger $(\mathrm{p}<0.01)$.

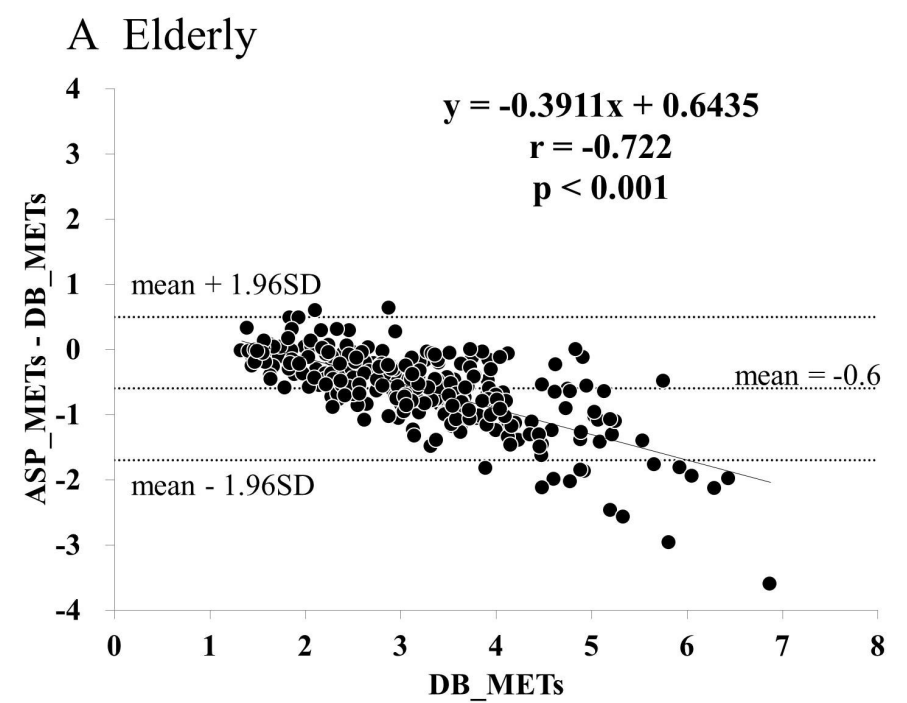

\section{DISCUSSION}

In this study, METs during various activities, including household activities and walking, were evaluated in healthy elderly and younger adults using an ASP. As a result, a strong correlation was observed between ASP_METs and DB_METs in both Elderly and Younger. A significant difference was observed in ASP_METs compared with DB_METs between both groups, and

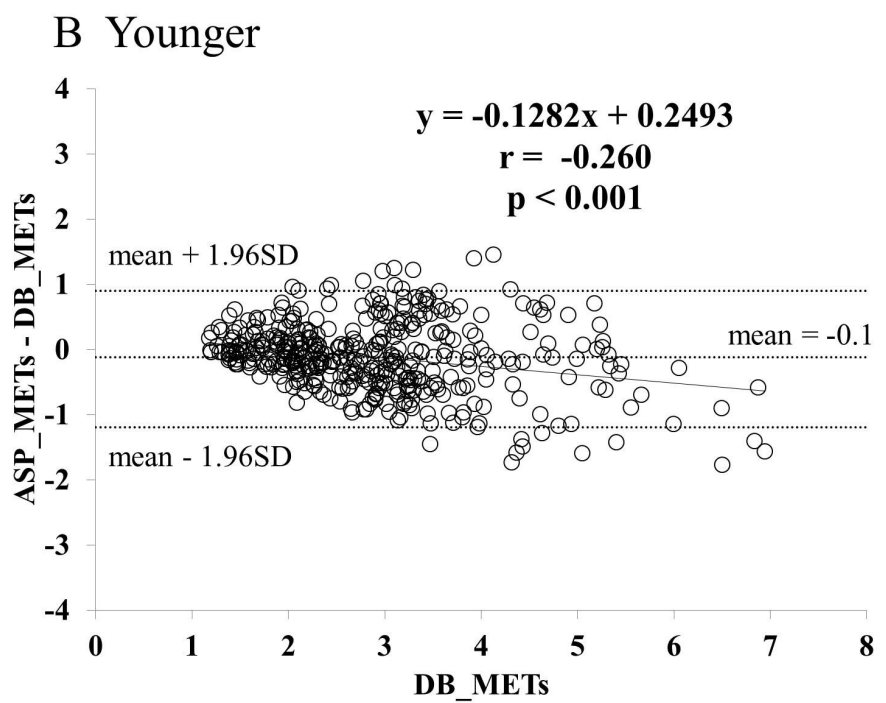

Figure 2 Error plots of ASP_METs in Elderly (A) and Younger (B). ASP_METs, METs predicted using Active style Pro HJA750C;DB_METs, metabolic equivalents (METs) measured using the Douglas bag method; Elderly, elderly group aged 60-80 years; Younger, adult group aged $20-59$ years. 


\begin{tabular}{|c|c|c|}
\hline & $\begin{array}{l}\text { Elderly } \\
\text { (60-80years) }\end{array}$ & $\begin{array}{l}\text { Younger } \\
\text { (20-59years) }\end{array}$ \\
\hline \multirow{2}{*}{$\begin{array}{l}\text { Filing of documents in } \\
\text { a sitting position }\end{array}$} & $-0.1 \pm 0.2$ & $0.0 \pm 0.2$ \\
\hline & $(-5.3 \pm 11.0 \%)$ & $(-0.4 \pm 13.8 \%)$ \\
\hline \multirow{2}{*}{$\begin{array}{l}\text { Filing of documents in } \\
\text { a standing position }\end{array}$} & $0.0 \pm 0.3$ & $0.1 \pm 0.4$ \\
\hline & $(-0.8 \pm 12.5 \%)$ & $(6.0 \% \pm 18.1 \%)$ \\
\hline \multirow[t]{2}{*}{ Wiping down } & $-0.5 \pm 0.4$ & $-0.2 \pm 0.5^{\star \star}$ \\
\hline & $(-14.4 \pm 11.9 \%)$ & $(-4.4 \pm 15.4 \%)$ \\
\hline \multirow[t]{2}{*}{ Dish washing } & $-0.6 \pm 0.3$ & $-0.4 \pm 0.3^{* *}$ \\
\hline & $(-25.4 \pm 9.3 \%)$ & $(-18.0 \pm 11.2 \%)$ \\
\hline \multirow{2}{*}{$\begin{array}{l}\text { Hanging and taking in } \\
\text { the laundry }\end{array}$} & $-0.5 \pm 0.3$ & $-0.3 \pm 0.4^{\star \star}$ \\
\hline & $(-19.1 \pm 9.9 \%)$ & $(-10.4 \pm 13.2 \%)$ \\
\hline \multirow[t]{2}{*}{ Vacuuming } & $-0.7 \pm 0.5$ & $-0.2 \pm 0.6^{* *}$ \\
\hline & $(-19.4 \pm 12.6 \%)$ & $(-4.2 \pm 18.7 \%)$ \\
\hline \multirow[t]{2}{*}{ Radio callisthenics } & $-1.0 \pm 0.5$ & $-0.5 \pm 0.4^{\star \star *}$ \\
\hline & $(-27.7 \pm 8.8 \%)$ & $(-15.9 \pm 11.8 \%)$ \\
\hline \multirow[t]{2}{*}{ Normal walking } & $-0.8 \pm 0.7$ & $0.2 \pm 0.6^{\star \star \star}$ \\
\hline & $(-17.6 \pm 13.3 \%)$ & $(7.7 \% \pm 15.5 \%)$ \\
\hline \multirow[t]{2}{*}{ Slow walking } & $-0.7 \pm 0.6$ & $0.2 \pm 0.5$ \\
\hline & $(-19.2 \pm 12.5 \%)$ & $(7.5 \% \pm 16.1 \%)$ \\
\hline \multirow[t]{2}{*}{ Fast walking } & $-1.0 \pm 0.8$ & $-0.1 \pm 0.8$ \\
\hline & $(-18.0 \pm 12.2 \%)$ & $(-0.2 \pm 15.2 \%)$ \\
\hline
\end{tabular}

Mean $\pm S D,{ }^{* \star} p<0.01,{ }^{\star \star *} p<0.001$.

Slow walking and fast walking were excluded from statistical analyses because the walking speed differed between the groups. Slow walking (Younger: $55 \mathrm{~m} / \mathrm{min}$, Elderly: $50 \mathrm{~m} / \mathrm{min}$ ), normal walking (both groups: $70 \mathrm{~m} / \mathrm{min}$ ) and fast walking (Younger: $100 \mathrm{~m} /$ $\mathrm{min}$, Elderly: $90 \mathrm{~m} / \mathrm{min}$ ).

ASP_METs, METs predicted by Active style Pro HJA-750C.

the error of ASP_METs in Elderly was higher than in Younger. ASP_METs significantly underestimated versus DB_METs in Elderly. Among activity types, the errors were approximately $5 \%$ for light activities, such as filing of documents while sitting or standing, in both groups, but they increased to approximately 20\% in Elderly for more intense activities of 3 METs or higher.

The accelerometer used in this study has an algorithm based on data from men and women aged 20-59 years. ${ }^{120}$ It has been reported that the relationship between DB_ METs and synthetic acceleration in children aged $6-12$ years was different from that in adults, ${ }^{22}$ but the validity of this accelerometer in the elderly aged 60 years and above is unclear. In the study by Park $e t a l^{19}$ using the older HJA-350IT model of the HJA-750C, the validity of this accelerometer during walking was evaluated in elderly subjects aged 65 years and above. As a result, METs predicted by HJA-350IT were underestimated compared with that measured using the Douglas bag method in healthy elderly people and the error in measurements was approximately $14 \%-17 \%$. In the present study, the METs during walking were similarly underestimated by approximately $17 \%-19 \%$ in Elderly. For activities other than walking, the errors of measurement were similar to those during walking.

There are a few previous studies that examined the cut-off value of MVPA using ActiGraph for the elderly subjects. ${ }^{15162324}$ Hooker et $a t^{24}$ investigated the 3 METs cut-points measured using an Actical activity monitor during walking and household activities. They demonstrated that the 3 METs cut-point were lower in the $\geq 65$ years old group than in a younger group (45-65 years), and that the accelerometer underestimated the activity level of elderly people. Corbett $e t a l^{16}$ evaluated the association between ActiGraph GT1M activity monitor counts and METs during walking in older adults (70-90 years). They demonstrated that the accelerometer may misclassify MVPA according to the traditional 2020 counts/min cut-point, and that there is a need to consider lower accelerometer activity count thresholds for assessing MVPA in the older adult population. Thus, previous studies have suggested that METs in elderly people estimated using an accelerometer was lower than the actual measured value during walking. Therefore, in the present study, we evaluated METs during activities other than walking, such as household activities, and obtained similar results. However, Chen $e t a \tilde{l}$ demonstrated that the elderly, especially people older than 75 years old tended to spend less time in MVPA compared with middle-aged people. Thus, underestimation of ASP_METs in MVPA activities would not have a large impact on evaluating total daily EE in the elderly.

ASP_METs were underestimated in Elderly and DB_ METs in Elderly were higher than those in Younger during the same activity. This result was considered to be related to a decrease in RMR in the sitting position and increased energy costs of exercise. In previous studies, it was demonstrated that RMR was lower in elderly people than in young people due to several factors, including ageing and a decrease in lean body mass. ${ }^{25} 26$ In the present study, RMR was also lower in Elderly than in Younger, although these two groups had a similar average body weight. On the other hand, some activities, such as walking, are weight-dependent rather than RMR-dependent. ${ }^{27}$ Moreover, regarding the energy cost of exercise, Mian et $a l^{28}$ demonstrated that the metabolic cost of average speed walking of elderly people was $31 \%$ higher than in younger people due to increasing antagonist muscle coactivation. Probably for these reasons, DB_METs were higher in Elderly, which caused underestimation of ASP_METs.

To evaluate factors related to DB_METs, stepwise multiple regression analysis was performed using $\mathrm{DB}_{-}$ METs as the dependent variable. As a result, ASP_METs, age and weight were extracted as factors in both groups. In particular, the influence of age on the prediction of actual METs was significantly greater in Elderly. For example, the partial regression coefficient of age for 
Table 4 Results of the multiple regression analysis in Elderly (A) and Younger (B)

\section{(A) Elderly}

\begin{tabular}{|c|c|c|c|c|c|c|c|c|c|}
\hline & & $\begin{array}{l}\text { Partial } \\
\text { regression } \\
\text { coefficient }\end{array}$ & SE & $\begin{array}{l}\text { Standardised } \\
\text { coefficient }\end{array}$ & T-value & $\begin{array}{l}\text { Significance } \\
\text { probability }\end{array}$ & $\mathbf{R}^{2}$ & $\begin{array}{l}\text { Adjusted } \\
\mathbf{R}^{2}\end{array}$ & $\begin{array}{l}\text { Significance } \\
\text { probability }\end{array}$ \\
\hline \multirow[t]{2}{*}{ Model 1} & (Constant) & 0.106 & 0.117 & & 0.906 & & 0.725 & 0.724 & 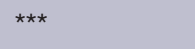 \\
\hline & ASP_METs & 1.191 & 0.043 & 0.852 & 27.483 & $* * *$ & & & \\
\hline \multirow[t]{3}{*}{ Model 2} & (Constant) & -2.017 & 0.446 & & -4.523 & $* * *$ & 0.747 & 0.745 & $* \star \star$ \\
\hline & ASP_METs & 1.198 & 0.042 & 0.856 & 28.719 & $* * *$ & & & \\
\hline & Age & 0.029 & 0.006 & 0.147 & 4.918 & $* \star \star$ & & & \\
\hline \multirow[t]{4}{*}{ Model 3} & (Constant) & -3.058 & 0.513 & & -5.962 & $* * *$ & 0.759 & 0.757 & $* * *$ \\
\hline & ASP_METs & 1.201 & 0.041 & 0.859 & 29.486 & $* \star *$ & & & \\
\hline & Age & 0.034 & 0.006 & 0.171 & 5.745 & $* * *$ & & & \\
\hline & Weight & 0.011 & 0.003 & 0.115 & 3.843 & $* \star *$ & & & \\
\hline
\end{tabular}

(B) Younger

\begin{tabular}{|c|c|c|c|c|c|c|c|c|c|}
\hline & & $\begin{array}{l}\text { Partial } \\
\text { regression } \\
\text { coefficient }\end{array}$ & SE & $\begin{array}{l}\text { Standardised } \\
\text { coefficient }\end{array}$ & T-value & $\begin{array}{l}\text { Significance } \\
\text { probability }\end{array}$ & $\mathbf{R}^{2}$ & $\begin{array}{l}\text { Adjusted } \\
\mathbf{R}^{2}\end{array}$ & $\begin{array}{l}\text { Significance } \\
\text { probability }\end{array}$ \\
\hline \multirow[t]{2}{*}{ Model 1} & (Constant) & 0.445 & 0.071 & & 6.298 & $* * *$ & 0.77 & 0.77 & $* \star \star$ \\
\hline & ASP_METs & 0.884 & 0.024 & 0.878 & 37.268 & $* \star \star$ & & & \\
\hline \multirow[t]{3}{*}{ Model 2} & (Constant) & -0.309 & 0.133 & & -2.32 & * & 0.792 & 0.791 & $* \star \star$ \\
\hline & ASP_METs & 0.885 & 0.023 & 0.879 & 39.187 & 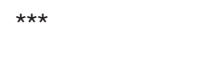 & & & \\
\hline & Weight & 0.012 & 0.002 & 0.147 & 6.563 & $* * *$ & & & \\
\hline \multirow[t]{4}{*}{ Model 3} & (Constant) & -0.504 & 0.143 & & -3.521 & $* \star \star$ & 0.798 & 0.796 & $\star \star \star *$ \\
\hline & ASP_METs & 0.884 & 0.022 & 0.878 & 39.623 & 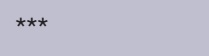 & & & \\
\hline & Weight & 0.01 & 0.002 & 0.126 & 5.503 & $\star \star \star ~$ & & & \\
\hline & Age & 0.008 & 0.002 & 0.079 & 3.44 & $\star \star *$ & & & \\
\hline
\end{tabular}

Dependent variable: METs measured using Douglas bag method (DB_METs).

Independent variables: age, sex, weight, body mass index (BMI) and METs predicted using Active style Pro HJA-750C (ASP_METs). ${ }^{*} \mathrm{p}<0.05,{ }^{* *} \mathrm{p}<0.01,{ }^{* * *} \mathrm{p}<0.001$.

ASP_METs, METs predicted by Active style Pro HJA-750C.

Elderly indicates that a difference of 10 years old leads to an error of 0.34 MET value. Ortega and Farley ${ }^{29}$ demonstrated that the energy cost during walking was higher in elderly people than in young people, and the difference between the two groups was $14 \%$ at minimum speed but $34 \%$ at maximum speed, and increasing with the walking speed. In another study, the energy cost during walking was high in obese or overweight elderly people, and excess weight was found to be related to an increase in energy cost in the elderly. ${ }^{30}$ These factors, especially age, may be cause for the different relations between ASP_METs and DB_METs in Elderly and Younger. However, although it is tentative, ASP_METs obtained for Elderly can be adjusted using regression coefficients indicated in table 4 .

\section{Limitations}

This study has some limitations. The first is that the subjects were elderly people capable of walking without assistance. Elderly people have widely varying physical abilities, and as the importance of physical activity measurement for the elderly is growing with recent population ageing, studies on elderly people with low physical function levels for who find it difficult to walk without assistance are also necessary. The second was that we could not provide sufficiently robust correction formulae. We could adjust ASP_METs using results obtained by the regression analysis, but the regression coefficients from 29 elderly may not be sufficiently robust. Thus, it is necessary to evaluate in a larger number of subjects. The third was that the maximum age of participants was 80 years. As the number of people older than 80 years is increasing in Japan, validation for such individuals is necessary. The last was the lack of information on body composition in this study. More detailed body composition measurements (eg, Dual energy X-ray absorptiometry) would have benefited to better understand whether the differences in error by age were truly age-related or simply from differences in fat-free mass between elderly and younger participants. 


\section{CONCLUSIONS}

In this study, METs predicted using a triaxial accelerometer and METs measured using the Douglas bag method during the same activities were compared between elderly and younger participants. A strong correlation was found between predicted METs and actual METs in both groups. A significant difference was observed in predicted METs compared with actual METs in both groups, especially in elderly participants. Thus, it should be kept in mind that predicted METs significantly underestimated against actual METs in the elderly. In addition, the greater underestimation for higher-intensity activities was noted in Elderly. A stepwise multiple regression analysis revealed that predicted METs, age and weight were related to actual METs in both groups.

The degree of correlation between predicted and actual METs was comparable in elderly and younger participants, but the prediction errors were greater in elderly participants, particular at higher-intensity activities, which suggests that different predicting equations may be needed for the elderly.

Acknowledgements We give our heartfelt thanks to the participants in this study. We also wish to thank the staffs of the National Institute of Health and Nutrition and of Omron Healthcare Co., Ltd.

Contributors SHN, TAA, TOA, SAN, CU and ST designed the study and participated in data collection. SHN conducted the statistical analysis and prepared original draft. All authors have been involved in revising the manuscript and approved the final manuscript.

Funding The authors have not declared a specific grant for this research from any funding agency in the public, commercial or not-for-profit sectors.

Competing interests SHN is employee of Omron Healthcare Co., Ltd. YO received consultant fees from Omron Healthcare Co., Ltd. SK and ST received a research grant from Omron Healthcare Co., Ltd, respectively.

Patient consent for publication All participants provided signed informed consent before the study.

Ethics approval All procedures involving human subjects were approved by the Ethics Committee of the National Institutes of Biomedical Innovation, Health and Nutrition in Tokyo, Japan.

Provenance and peer review Not commissioned; externally peer reviewed. Data availability statement Data are available upon reasonable request.

Open access This is an open access article distributed in accordance with the Creative Commons Attribution 4.0 Unported (CC BY 4.0) license, which permits others to copy, redistribute, remix, transform and build upon this work for any purpose, provided the original work is properly cited, a link to the licence is given, and indication of whether changes were made. See: https://creativecommons.org/ licenses/by/4.0/.

\section{ORCID iD}

Sho Nagayoshi http://orcid.org/0000-0003-3482-7420

\section{REFERENCES}

1 WHO. Good health adds life to years [Internet], 2012. Available: http://www.who.int/ageing/publications/whd2012_global_brief/en/ [Accessed 13 Aug 2018].

2 Statistics Bureau. Statistical Handbook of Japan. Available: https:// www.stat.go.jp/english/data/handbook/index.html [Accessed 14 Nov 2018].

3 GBD_report_2004update_part3.pdf. Available: http://www.who.int/ healthinfo/global_burden_disease/GBD_report_2004update_part3. pdf [Accessed 13 Aug 2018].
4 World Health Organization. Global recommendations on physical activity for health. Geneva: World Health Organization, 2010.

5 Chen T, Kishimoto H, Honda T, et al. Patterns and levels of sedentary behavior and physical activity in a general Japanese population: the Hisayama study. J Epidemiol 2018;28:260-5.

6 de Rezende LFM, Rey-López JP, Matsudo VKR, et al. Sedentary behavior and health outcomes among older adults: a systematic review. BMC Public Health 2014;14:333.

7 Shephard RJ. Limits to the measurement of habitual physical activity by questionnaires. Br J Sports Med 2003;37:197-206.

8 Rikli RE. Reliability, validity, and methodological issues in assessing physical activity in older adults. Res Q Exerc Sport 2000;71 Suppl 2:89-96.

9 Crouter SE, Clowers KG, Bassett DR. A novel method for using accelerometer data to predict energy expenditure. J Appl Physiol 2006;100:1324-31.

10 Bonomi AG, Goris AHC, Yin B, et al. Detection of type, duration, and intensity of physical activity using an accelerometer. Med Sci Sports Exerc 2009;41:1770-7.

11 Crouter SE, Kuffel E, Haas JD, et al. Refined two-regression model for the ActiGraph accelerometer. Med Sci Sports Exerc 2010;42:1029-37.

12 Oshima Y, Kawaguchi K, Tanaka S, et al. Classifying household and locomotive activities using a triaxial accelerometer. Gait Posture 2010;31:370-4

13 Matthew CE. Calibration of accelerometer output for adults. Med Sci Sports Exerc 2005;37:S512-22.

14 Park J, Ishikawa-Takata K, Tanaka S, et al. Effects of walking speed and step frequency on estimation of physical activity using accelerometers. J Physiol Anthropol 2011;30:119-27.

15 Hall KS, Howe CA, Rana SR, et al. METs and accelerometry of walking in older adults: standard versus measured energy cost. Med Sci Sports Exerc 2013;45:574-82.

16 Corbett DB, Valiani V, Knaggs JD, et al. Evaluating walking intensity with Hip-Worn Accelerometers in elders. Med Sci Sports Exerc 2016;48:2216-21.

17 Murakami H, Kawakami R, Nakae S, et al. Accuracy of wearable devices for estimating total energy expenditure: comparison with metabolic chamber and doubly labeled water method. JAMA Intern Med 2016;176:702-3.

18 Montoye AHK, Pivarnik JM, Mudd LM, et al. Evaluation of the activPAL accelerometer for physical activity and energy expenditure estimation in a semi-structured setting. J Sci Med Sport 2017;20:1003-7.

19 Park J, Ishikawa-Takata K, Tanaka S, et al. Accuracy of estimating step counts and intensity using Accelerometers in older people with or without assistive devices. J Aging Phys Act 2017;25:41-50.

20 Ohkawara K, Oshima Y, Hikihara Y, et al. Real-Time estimation of daily physical activity intensity by a triaxial accelerometer and a gravity-removal classification algorithm. Br J Nutr 2011;105:1681-91.

21 Weir JBDEB. New methods for calculating metabolic rate with special reference to protein metabolism. J Physiol 1949;109:1-9.

22 Hikihara Y, Tanaka C, Oshima Y, et al. Prediction models discriminating between nonlocomotive and locomotive activities in children using a triaxial accelerometer with a gravity-removal physical activity classification algorithm. PLoS One 2014;9:e94940.

23 Copeland JL, Esliger DW. Accelerometer assessment of physical activity in active, healthy older adults. J Aging Phys Act 2009;17:17-30.

24 Hooker SP, Feeney A, Hutto B, et al. Validation of the actical activity monitor in middle-aged and older adults. $J$ Phys Act Health 2011;8:372-81.

25 Campbell JA, D'Acquisto LJ, D'Acquisto DM, et al. Metabolic and cardiovascular response to shallow water exercise in young and older women. Med Sci Sports Exerc 2003;35:675-81.

26 Byrne NM, Hills AP, Hunter GR, et al. Metabolic equivalent: one size does not fit all. J Appl Physiol 2005;99:1112-9.

27 Taguri E, Tanaka S, Ohkawara K, et al. Validity of physical activity indices for adjusting energy expenditure for body size: do the indices depend on body size? J Physiol Anthropol 2010;29:109-17.

28 Mian OS, Thom JM, Ardigò LP, et al. Metabolic cost, mechanical work, and efficiency during walking in young and older men. Acta Physiol 2006;186:127-39.

29 Ortega JD, Farley CT. Individual limb work does not explain the greater metabolic cost of walking in elderly adults. J Appl Physiol 2007;102:2266-73.

30 Laroche DP, Marques NR, Shumila HN, et al. Excess body weight and gait influence energy cost of walking in older adults. Med SCi Sports Exerc 2015;47:1017-25. 